\title{
Melhorias de desempenho dos processos em serviços de saúde através da aplicação de ferramentas Lean Healthcare.
}

\section{Isabela Victória Soares Andriani e Paulo Sérgio de Arruda Ignácio.}

\section{Resumo}

O projeto se trata da análise da aplicabilidade das ferramentas Lean Healthcare no setor de Hemodiálise de um Hospital localizado no interior de São Paulo. A metodologia elaborada por Yin foi utilizada para estruturar a pesquisa. O resultado da análise indicou oportunidades de melhoria nos tempos de espera dos processos. O resultado inicial foi o uso de um carrinho para transporte dos kits de hemodiálise para a sala do processo, dessa forma os funcionários não precisam se deslocar muitas vezes até o estoque que é distante e os pacientes esperaram por menos tempo o início do procedimento.

Palavras-chave: Lean Thinking, Lean Healthcare, Nefrology.

\section{Introdução}

Womack, Jones (2003) definem o Lean como uma maneira de se fazer mais com menos, reduzindo esforços humanos, o tempo de lead time, desperdícios e espaço ocupado, ao mesmo tempo em que se fornece aos clientes exatamente o que eles querem com uma boa qualidade.

O objetivo primário desta pesquisa é avaliar o desempenho dos processos operacionais na prestação de serviços de saúde em hemodiálise, sobre uma determinada casa de saúde do interior do estado de São Paulo. Os objetivos secundários são: verificar a aplicação das ferramentas do Lean Healthcare em uma unidade interna da empresa objeto de estudo e avaliar as melhorias obtidas na aplicação das ferramentas.

\section{Resultados e Discussão}

Para seleção de artigos, com o uso das palavras-chave, foram separados 300 artigos revisados dentre os anos 2010 e 2018 para cada uma delas, com exceção de Nefrology para qual foram encontrados apenas 35 artigos, como ilustrado na Figura 1. Pela análise, é possível perceber o destaque para quality improvement, para lean e palavras que se relacionam principalmente ao lean healthcare

Figura 1. Relação entre artigos de palavras-chave Lean Healthcare e Nefrology.

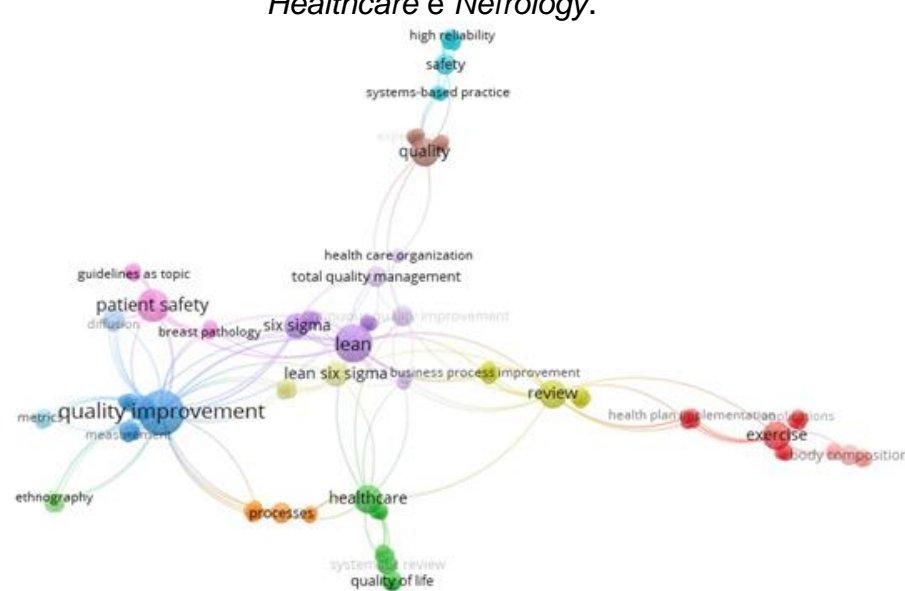

Na aplicação foi elaborado o Mapa de Fluxo de Valor do processo de realização da Hemodiálise na empresa objeto de estudo, como ilustrado na Figura 2.

Cada vez que um funcionário precisa ir até o estoque e voltar são cerca de 23 metros percorridos. Um paciente idoso que consegue andar sem auxílio de muleta, cadeira de rodas ou maca, chega a percorrer mais de 50 metros pelo local desde o momento em que entra até a sua saída. Existem tempos de espera que poderiam ser reduzidos se houvesse mais recursos disponíveis tanto na triagem quanto na liberação. A organização do estoque poderia facilitar a procura dos funcionários por itens específicos.

Figura 2. MFV do setor de Hemodiálise da empresa objeto de estudo.

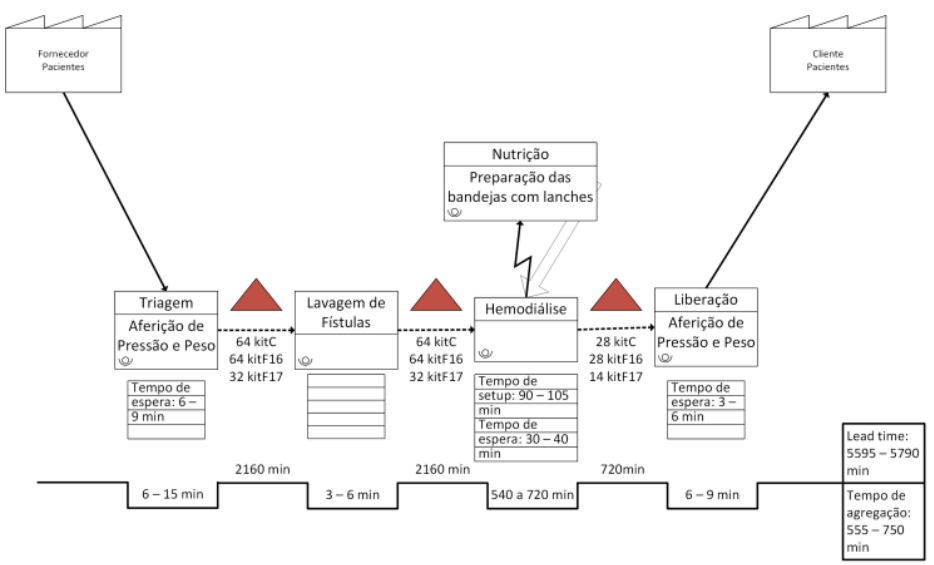

Como melhoria sugerida, foi aplicado o uso de um carrinho para transporte dos kits para os pacientes. Já no momento em que a sala do procedimento começa a ser limpa, um dos funcionários é responsável por pegar a demanda do turno no estoque e separar no carrinho. Com o início da implementação dessa mudança, o tempo de espera foi reduzido em média 7 minutos, representando uma redução de cerca de $20 \%$ no tempo do processo.

\section{Conclusões}

A filosofia Lean permite que a situação atual de uma determinada empresa seja analisada e que melhorias sejam propostas baseadas nos seus princípios e ferramentas. Neste caso, pode-se observar que 0 desenho físico e os tempos de espera eram oportunidades de melhoria. Com a proposta do carrinho para transporte de material, houve inicialmente uma redução de $20 \%$ do tempo de espera.

SARANTOPOULOS, et al. O que é esse tal de Lean Healthcare? Campinas: Editora Pedro João, 2017.

WOMACK, James P. ; JONES, Daniel T. Lean Thinking: Banish Waste and Create Wealth in Your Corporation. Nova lorque: Free Press, 2003. 